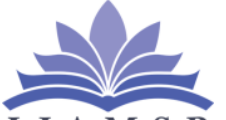

International Journal of

\title{
GIS BASED DECISION SUPPORT SYSTEMS IN AGRICULTURE
}

\author{
Yogesh Sharma, \\ Project Manager, Cognizant,Hyderabad \\ yogeshsharma505@gmail.com
}

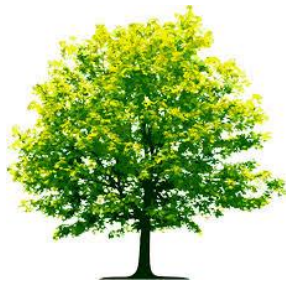

Keywords: GIS, Remote Sensing, Decision Support Systems, geostatistics, Spatial Data, Spatial Analysis

\begin{abstract}
A B S T RA C T
Decision Support Systems (DSS) give a structure for incorporating database administration frameworks, diagnostic models, and illustrations, with a specific end goal to enhance the basic leadership process. The choice emotionally supportive network idea was stretched out to the spatial setting by incorporating GIS and DSS into Spatial Decision Support Systems (SDSS). In light of absence of PC programming to create easy to use interfaces previously, GIS has not been utilized as a major aspect of SDSS. Rather GIS has been utilized to create and store spatial information which were then utilized as contributions for the expository models. GIS was utilized freely to show maps by contributing consequences of the diagnostic models. Much research has been done on the utilization of GIS in the representation of the consequences of the diagnostic models. Creating easy to understand graphical interfaces in consolidating logical models into GIS to touch base at SDSSs is one of the dynamic zones in farming administration. Some, such cases are examined in this paper. Accuracy cultivating, a blend of GIS, GPS recipients, nonstop yield sensors, geostatistics and variable rate utensils is an inventive way to deal with routine with regards to economical farming. Alternate SDSS applications talked about in this paper are on watershed administration, trim efficiency administration and arrangement choice examination.
\end{abstract}

Citation: Yogesh Sharma (2018). GIS Based Decision Support Systems In Agriculture. International Journal of Advanced Multidisciplinary Scientific Research (IJAMSR ) ISSN:2581-4281 Vol 1, Issue 9, November, 2018, \#Art.911, pp 1-9

\section{Introduction}

Expanding sustenance requests because of high rates of populace development and real changes in political and financial and social frameworks have made a critical need to grow new and reconsider numerous current rural frameworks and practices. India is portrayed by a high populace with a bigger development rate ( 2\%/annum). The eager attack of statistic weight (16 - 17 extra individuals every year) on India's characteristic assets and high production increases constrained to blessed by the gods flooded zones, have however put a question mark on the strength and suitability of Indian 


\section{International Journal of Advanced Multidisciplinary Scientific Research (IJAMSR) ISSN:2581-4281}

horticulture (Katyal et. al, 1996). Presently, like never before, leaders at all levels require an expanding measure of data to enable them to comprehend the conceivable results of their choices and create plans and approaches for taking care of the expanding demand of sustenance necessities without harming the normal asset base.

Decision Support Systems (DSS) are "intelligent PC based frameworks that assistant chefs use the information and models to take care of unstructured issues" Turban, 1995). These apparatuses enhance the execution of the leaders while lessening the time and HR required for dissecting complex choices. Spatial Decision Support Systems (SDSS) manage spatial measurement through digitized Geo - referenced spatial databases. Farming is basically a spatial marvel which isn't autonomous of the area. GIS is the apparatus and innovation that handle different spatial databases, and is a youthful zone of data innovation. This spatial data innovation permits to look at and break down a more extensive scope of farming related assets, for example, soil, climate, hydrology, different financial factors at the same time and precisely. Concurrent examination of these factors in a GIS domain prompts a superior comprehension of how agrarian frameworks work and connect over space and time. This understanding prompts to create steady and supportable dynamic farming advancements.

DSS with GIS apparatus can better compose and break down spatial information, deliver the issues identified with spatial and worldly changeability of different normal assets on which the execution of rural frameworks depends. Spatial databases created in GIS as a contribution to investigative models, for example, reproduction models and measurable model empowers to show agribusiness from field to national and worldwide scales precisely. The yield on zone activity designs at various scales can be seen through maps. These maps give knowledge and comprehension of spatial and fleeting connections of different horticultural frameworks and assets after some time. The data substance and exactness of these maps relies upon the size of the spatial information procurement. Connecting of spatial examination and reproduction models to GIS databases is one of the flow zones of dynamic research in numerous parts of the world. These spatial data frameworks and choice emotionally supportive networks help to oversee different farming frameworks effectively finished space to meet the changing nourishment requests without harming our normal asset base. In such manner GIS can be looked as a fundamental and focal instrument for creating spatial choice emotionally supportive networks. In this paper a few utilizations of SDSS and in rural research are talked about.

\section{Spatial Decision Support Systems For National And} Local Plan Decision

We run over number of papers in logical writing on the utilizations of time arrangement examination of the information gathered by the State Directorate of Economics and insights and other Government Statistical associations. For instance, considers on rural development and evaluating the elements of trimming design, arrive, utilize, animals, populace, water system, compost utilize and so forth., are normal. Constantly the information is accessible at local level yet the examination is being performed on the total information at national or territorial or state level contingent upon the investigation. However, investigation of total 


\section{International Journal of Advanced Multidisciplinary Scientific Research (IJAMSR) ISSN:2581-4281}

information does not surmise about area particular patterns and spatial examples which are extremely basic for agrarian strategy, arranging and administration.

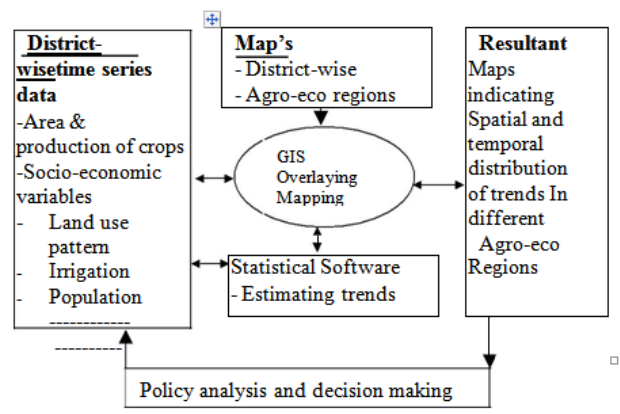

Fig.1 Components of spatial decision support system for policy decisions

Katyal and Narayana Reddy (1997) considered the adjustments in the zone and profitability of rain-fed crops Sorghum, Pearl millet, Pigeonpea, and Chickpea and so forth by connecting the time arrangement area astute information to local guide of India. Promote Agro-Eco districts were (Siegalet al, 1992) overlaid. These maps uncover the spatial patterns in the territory and profitability of rain-fed trims in various Agra-Eco areas separated from worldly patterns. Their investigation draws out the need to rejuvenate the endeavors on settling and quickening the efficiency levels even in Agra-Eco Region, which is the real sorghum zone. Asset portrayal is one of the vital uses of GIS in horticulture. Overlaying the maps demonstrating the spatial appropriation of different yield measurements, for example, profitability, water system, manure and so forth., against asset portrayal maps empowers to evaluate trim execution regarding asset capacities. Different parts of this SDSS is appeared in Fig.1. These assistance in creating methodologies for ideal asset use in future.

\section{Spatial Decision Support Systems For Crop Output Administration At Local Level}

The territorial Productivity examination includes assessing spatial soil and climate fluctuation, recognizing ideal yield administration rehearses, and anticipating profitability of the area under various climatic and administration situations. This investigation can help provincial organizers and strategy creators in the outlining real estate and dissemination of territories with high efficiency and creating administration proposals for various yields. Lal et., (1993) expanded the extent of the pertinence of site-particular harvest reproduction models, for example, DSSAT (choice emotionally supportive network for the Agra technology exchange) to territorial arranging efficiency and approach examination by joining their abilities with ARC/INFO GIS. An interface was produced to join DSSAT models with ARCVIEW. In this joined system (Fig. 2), reproduction models anticipate data on yield and other harvest related yields for various homogeneous soil and climate blends, and GIS totals data from singular units, shows maps, and furthermore introduces brings about unthinkable arrange for the examination district. They utilized this arrangement of examination for three locales having significant soil and climate inconstancy. To produce yield databases, a few a huge number of recreations are to be made utilizing DSSAT for an assortment of administration mixes for various soil and climate conditions in the investigation locales. The contribution for this sort of study incorporates soil maps, soil study reports, day by day, precipitation, day by day most extreme and least temperatures, and sunlight based radiation esteems. The consequences of the examination of Lal et., show 


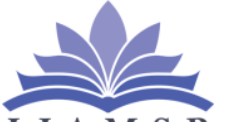

\section{International Journal of Advanced Multidisciplinary Scientific Research (IJAMSR) ISSN:2581-4281}

impressive variety in ideal planting dates and yield levels under rain fed conditions. Their examination effectively exhibits the extent of the pertinence of siteparticular models to provincial arranging and profitability investigation by joining their abilities with GIS. Singh et., (1993) showed the utilization of GIS to research, nitrogen manure effectiveness in Maharashtra state, utilizing sorghum trim reproduction demonstrate combined with a GIS. The spatial databases of the GIS contain data on soils, climate and different information sources required by the sorghum demonstrate. The framework permits local examinations and the yield can be as far as maps. Subsequently, these consolidated devices can be utilized for portraying the district, finding high yielding and dangerous regions and evaluating their efficiency under various administration methodologies

\section{Output Administration At Farm Level}

For the most part we lead field trials in some measurable plan, which derives the outcomes in light of factual hugeness tests. The unaccounted inconstancy called exploratory blunder is credited to wild ecological elements. Then again PC based choice emotionally supportive networks, for example, DSSAT are created to comprehend the collaboration between different yield administration alternatives and condition. Hoogenboomet. al. (1993) utilized DSSAT models at explore, cultivate level by building up a product interface with ARCVIEW. The primary goal of their investigation was to grow the utilization of harvest reenactment models through a linkage with GIS and spatial soil databases. The second target was to apply this framework to ponder the dispersion of yield, water utilize, and other agronomic factors as a component of soil spatial inconstancy on a ranch level. The quality of a
GIS is that we can make different spatial database layers for topology, rise, soil profundity, soil write, climate, arrives utilize, and some other related data utilizing GIS. One could, for example, digitize a dirt guide to give the essential guide layer and build up a property database for soil composition, soil family, soil affiliation, $\mathrm{pH}$, slant and other soil physical and substance attributes. Each layer can be overlaid to make homogeneous polygons, each with one of a kind qualities in light of the arrangement of each layer.

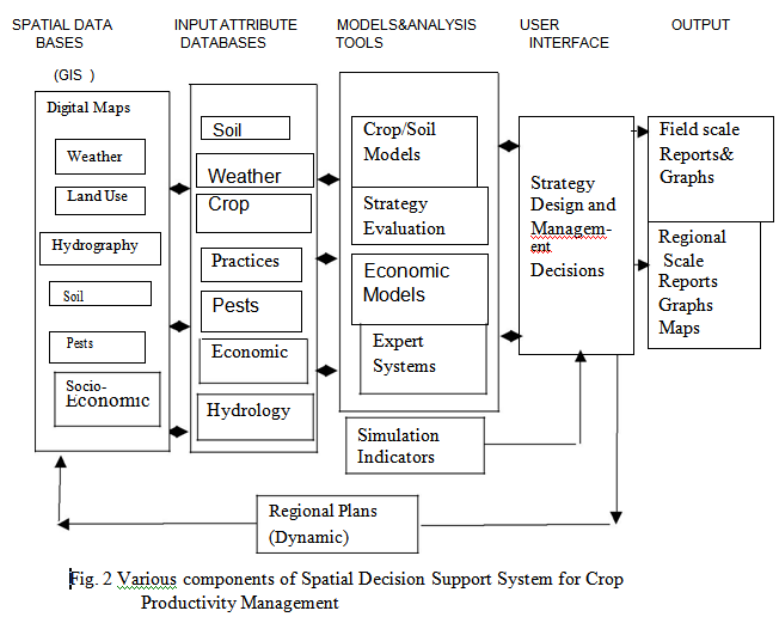

The GIS Crop-display framework would then be able to be utilized to reenact trim development and advancement for every polygon or field with various qualities. The aftereffects of the investigation by Hoogenboomet. al., for the harvests become under rainfed conditions demonstrated a solid spatial variety. Thus, it might be conceivable to catch the inconstancy in edit yields satisfactorily by overlaying numerous dirt attributes utilizing GIS and suitable systematic models. This aides in settling on the choices on changing information use at field level for feasible harvest efficiency administration 


\section{International Journal of Advanced Multidisciplinary Scientific Research (IJAMSR) ISSN:2581-4281}

Spatial Decision Support Systems For Watershed Administration

Harvest Planning in light of Watershed, as a unit is vital to streamlining the utilization of constrained Water assets for amplifying and maintaining the profitability under rain-fed conditions. Topographical data frameworks have been effectively coordinated with circulating parameter, single occasion, water quality models, for example, AGNPS (Agricultural Non Point Source) and ANSWERS (Areal Nonpoint Source Watershed Environmental Response Simulation). These angles are extremely very much talked about by Garg (1994). Other broadly utilized models incorporate EPIC (Williams et. al, 1983), CREAMS (Knisel, 1980) and SWRRB (Arnold et. al, 1990). The measure of time, skill and cost required for getting input information for running the models are enormously expanded. For instance, a straightforward model like USLE requires just six sources of info, while a spatially dispersed, single - occasion show like AGNPS requires 22 contributions for every cell or matrix inside an examination territory. The need can differ essentially between and inside models, contingent upon the inquiries to be replied, along these lines enormously expanding the cost, time and intricacy of investigating comes about. The coordination of GIS with disseminated parameter models can kill a significant number of the constraints related to the utilization of these models especially for input information readiness. Srinivasan and Engel (1991) coordinated the AGNPS model to show and encourage examination of model yield. Rewerts and Engel (1991) coordinated the ANSWERES show with the GRASS GIS to construct contributions to run the model. Both AGNPS and ANSWERS are singleoccasion appropriated parameter models that require a watershed to be isolated into square lattices and resemble like a raster-based GIS., where the information is arranged in a framework - like cluster. There are huge contrasts between the single-occasion and nonstop time appropriated models, both in techniques for extricating data sources and strategies for dissecting and showing yields, because of time segment associated with constant time displaying.

Constant time, disseminated parameter models consider the bowl or watershed partitioned into sub-bowls in light of geology, soil and land utilize and in this manner protect the spatially-appropriated parameters and homogeneous attributes inside a sub-bowl. Gathering of contributions for such models is regularly troublesome because of the level of collection and the idea of spatial appropriation. To conquer this issue Srinivasan and Arnold (1994) built up a GIS interface to mechanize contributions to a consistent time, conveyed parameter show called the Soil and Water Assessment Tool (SWAT). Advanced height show (DEM) made in GIS is an imperative contribution to this model. Given an information surface, for example, DEM, the hydrologic displaying instruments can be utilized to create matrices that encode the stream bearing and stream aggregation for every phone or lattice speaking to nearby and normal watersheds and seepage arrange. Fig. 3 demonstrates the GIS input interface structure for SWAT show. Jain and Saraf (1995) utilized GIS ILWIS (Integrated Land and Water Information System) to anticipate normal soil misfortune through USLE (Universal Soil Loss Equation) show. 


\section{International Journal of

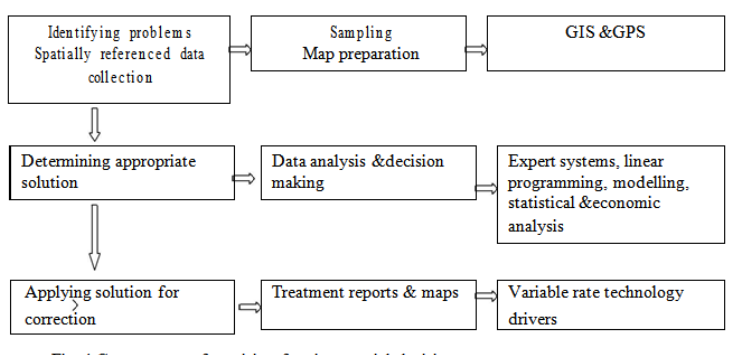

Fig. 4 Components of precision farming spacial decision support system

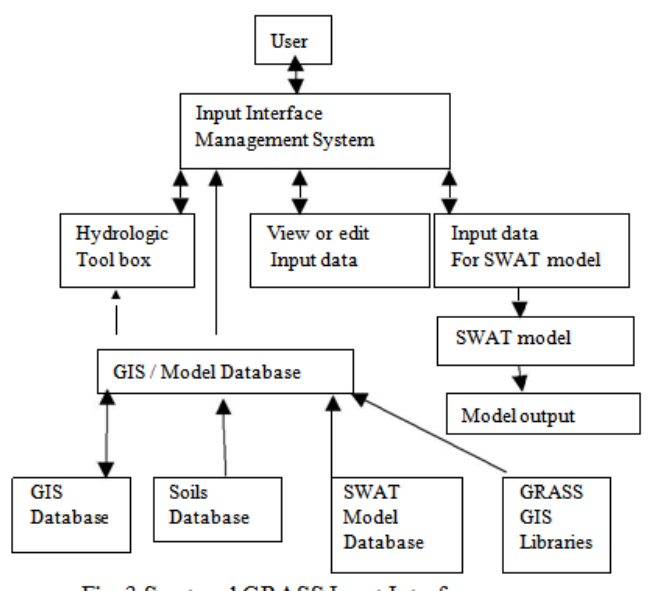

Fig. 3 Swat and GRASS Input Interface

\section{Spatial Decision Support System For Correctness} Agricultural

The degree and rate of progress now happening in the improvement of data advances have opened the route for huge changes in edit creation administration and rural basic leadership. This vision is reflected in exactness cultivating. Exactness or site particular cultivating expects to coordinate the utilization of seed, manure, pesticides and water inside fields in ways that streamline cultivate returns and limit concoction inputs and ecological perils. These exactness cultivating frameworks use some blend of GPS beneficiaries, constant yield sensors, remote detecting, geostatistics, and variable rate treatment instruments with GIS (Fig. 4) . GPS (Global Positioning System) is one of the numerous new advancements, adding to exactness cultivating, and is the one that truly puts the accuracy into cultivating for most site particular operations.

Accuracy cultivating innovation enables agriculturists to settle on educating financial choices about information utilize, while decreasing or maintaining a strategic distance from long haul ecological corruption. The appropriation of this innovation requires precise geological maps demonstrating physical and compound properties and the devices to apply the contributions according to the spatial inconstancy. The ideas typified in accuracy farming offer the guarantee of expanding profitability while diminishing generation costs and limiting natural effects. Accuracy agribusiness is viewed as a suite of advancements comprising of harvests, climate, bugs buildings, and showcasing game plans as opposed to a solitary innovation. Every one of these segments has the normal component of expanding the data force of agribusiness. Exactness cultivating/horticulture requires new ways to deal with examine that are planned unequivocally to enhance comprehension of the perplexing cooperation between various components influencing crop development and homestead basic leadership. Understanding the mind boggling collaborations among the various elements influencing the crop development is the establishment of any endeavor to enhance administration frameworks. Exactness agribusiness is changing the manner by which horticultural research can be an expert. The age of enormous measures of information on homestead will empower dynamic experimentation that could supersede 


\section{International Journal of Advanced Multidisciplinary Scientific Research (IJAMSR) ISSN:2581-4281}

the utilization of customary exploratory plots. The agrarian frameworks may need to develop so advancement and learning can abuse both conventional research plot investigations and data caught from real field operations. Fusing data about changeability in soils, dampness, supplements, and nuisance populaces into basic leadership requires a comprehension of harvest development in an ecological setting. Conventional plant and soil science look into has not been intended to give this sort of data. The present worldwide is that of the controlled trials, in which at least one variable are fluctuated while others are held consistently. Such a test configuration relates ineffectively to a genuine ranch setting, in which various components change at the same time. Such analyses give little data about how reactions to varieties in any one factor change as different condition change. New data advances will be required to make, the more definite and convenient choices vital for accuracy horticulture. Presentation of new detecting methods will empower the accumulation of a phenomenal number of soil, harvest, irritation and climate perceptions. Maps made utilizing GIS programming can be utilized amid field operations to make more exact and convenient utilization of information sources. Multidisciplinary research will be expected to coordinate estimation strategies and explanatory procedures with editing, creation inquiries important to successfully comprehend and utilize data about the genuine fluctuation of quantifiable parameters inside homestead fields. Database administration and picture handling strategies are expected to remove helpful data from huge informational collections. Geofactual techniques must be progressed both for all the more adequately test and for all the more precisely add scanty information. Spatial investigation techniques and spatially express segments in edit models ought to be assessed and adjusted under field conditions, and connected to GIS to encourage exact examination and surmising from gathering accuracy horticultural information.

\section{Conclusion}

In the twenty-first century, rural expert utilizing data advances will assume an inexorably critical part in trim generation and regular asset administration. Expanded utilization of manures, pesticides and different chemicals have added to the upgrade of farming's profitability in late decades. In any case, as of now, horticulture creation is confronting numerous difficulties, for example, expanded cost of generation, lack of water system water, antagonistic effects of agribusiness on nature and so on. For nations like India it is a testing assignment to meet the sustenance requests of the developing populace in future. Further, to make due in the exceedingly focused world market of horticultural wares in perspective of globalization, agrarian makers must create profoundly quality items at low costs while utilizing naturally solid practices. In this setting GIS has a noteworthy part to play in the basic leadership process in horticulture at different levels i.e., field, provincial, national and worldwide levels. GIS is one of the critical apparatus of Information Technology (I.T) exceedingly significant to agribusiness. This innovation permits to look at and handle a more extensive scope of spatial information bases, for example, soils, hydrology, climate and so on and incorporate with financial factors. Concurrent examination of these factors prompts a superior under remaining of different horticultural related process and their communications over space and time. This prompts portrayal of assets precisely and to recognize fitting areas to target new innovations every once in a while. 


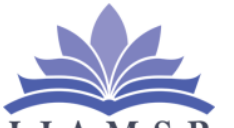

\section{International Journal of Advanced Multidisciplinary Scientific Research (IJAMSR) ISSN:2581-4281}

Connecting of reproduction models, for example, trims recreation models, hydrologic models, factual models for GIS databases is one of the ebb and flow dynamic regions of research. By interfacing these models, GIS is rising as an effective spatial choice emotionally supportive network. Product recreation models are intense instruments just when they are appropriately approved for the delegate areas. It can be reasoned that connecting spatial databases, investigative and reenactment models with GIS is a perfect method to consider the spatial variety and conveyance of harvest yield, water utilize and other agronomic factors as a component of soil and climate conditions and administration procedures. Further, GIS is a perfect apparatus for trim anticipating watershed premise since computerized height models (DEM) made in GIS can be coordinated with other spatial data, including land utilize design acquired from remote detecting information every now and then. GIS incredibly lessens the handling time for information planning as the measure of information, data expected to execute these reproduction models is colossally expanded. SDSSs depicted in this paper would point towards an adaptable coordinated framework, based on a GIS stage, to manage spatial information and controls and an examination module which could change from investigation to clarify in an intelligent, iterative and participatory way.

\section{References}

1) Crop Management. Committee on Assessing crop yield. National Academy Press, Washigton

2) Dadi, Sanyasinaidu. "USE OF GIS IN HYDROLOGICAL INVESTIGATIONS. " INTERNATIONAL JOURNAL OF MULTIDISCIPLINARY ADVANCED RESEARCH TRENDS.(2015): 67.

Web. <https://www.researchgate.net/publication/3210694 87_USE_OF_GIS_IN_HYDROLOGICAL_INVESTIGATI ONS>.

3) Dadi, Sanyasinaidu. "An Importunate Role of GIS in
Indian Retail Industry." MAT Journals-Journal of Remote Sensing GIS \& Technology. (2017):

Web.<http://www.matjournals.in/index.php/JORSGT/arti cle/view/2110>.

4) Dadi, Sanyasinaidu. "Remote Sensing and Geographic Information System for Jungle Administration." MAT matjournals-JOURNAL OF REMOTE SENSING GIS \& TECHNOLOGY (2017):

Web. <http://matjournals.in/index.php/JoADC/article/view /2128>.

5) Dadi, Sanyasinaidu. "GIS and Remote Sensing as Tool to Develop Applications for Natural Resource

Management." MAT -matjournals-JOURNAL OF REMOTE SENSING GIS \& TECHNOLOGY. (2017): Web. <http://www.matjournals.in/index.php/JORSGT/arti cle/view/2101>.

6) Dadi, Sanyasinaidu. "GIS and Remote Sensing For Site Specific Farming Area Mapping." MAT-matjournalsJournal of Analog and Digital Communications. (2017): Web. <http://matjournals.in/index.php/JoADC/article/view /2126>.

7) Dadi, Sanyasinaidu. "UNDERSTANDING THE CONCEPT OF VIRTUAL GLOBE FOR A GIS PERSONNEL." INTERNATIONAL JOURNAL OF MULTIDISCIPLINARY ADVANCED RESEARCH TRENDS. (2015):

Web. 〈http://ijmart.in/PreviousIssues/Sep-2015/4.pdf>,

8) Gark P.K. 1994 Geographical Information System as a tool for distributed hydrological modelling. GIS India Vol. 3 PP 27 -31

9) Hoogenboom, G.,Lal, H.,andD.D.Gresham 1993. Spatial yield prediction. An ASAE meeting presentation paper No. 93-3550. Hyatt regency, Chicago III, Dec. pp14-17 1993.

10) Katyal ,J.CandM.Narayana Reddy, 1997. Remote Sensing and GIS to address certain issues related to dryland agriculture. NNRMS, Bulletin, January, Vol.20; pp: 4-15.

11) Katyal, J.C., Kaushalya Ramachandran, Narayana Reddy, M. and C.A.Rama Rao. 1996. Indian AgricultureProfile of land resources, Crop performances and Prospects. Proc. South Asia regional Workshop on Regional Land Cover changes, sustainable Agriculture and their interactions with global change. COSTED, ICSU \& UNESCO, 16-19 December, 1996, Madras.

12) Knisel, W.G(ed.) 1980 . CREAMS : A field scale model for chemicals, runoff, and eroson from agricultural management system. USDA, Conservation Research Report No. 26, 643

13) Lal, H, G.Hoogenboom, J.P. Calixte, J.W.Jones, G.H. Beinroch, 1993. Using Crop Models and GIS for Regional Production Analysis. Transaction of ASAE 36(1): $177-$ 184.

14) Precision Agriculture in the $21^{\text {st }}$ Century, 1997 Geospatial and Information Technologies in

15) Rewerts, C.C., and B.A.Engle . 1991. ANSWERS on 
https://doi.org/10.31426/ijamsr.2018.1.9.911

I J A M S R

International Journal of Advanced Multidisciplinary Scientific Research (IJAMSR) ISSN:2581-4281

GRASS: Integrating a watershed simulation with GIS .ASAE paper No. 91-2621, American Society of Agricultural Engineers, St. Joseph, MI

16) Sehgal, J.L., Mandal, D.K., Mandal, C and S.Vadivelu (1992). Agro-Ecological Regions of India. National Bureau of Soil Survey \& Land Use Planning (ICAR) Nagpur. OXFORO \& IBH Publishing Co. Pvt. Ltd.

17) Singh, U., Brink, J.E., Thornton, P.K., and Christianson C.B. 1993. Linking crop models with geographic information system to assist decision making : A prototype for the Indian semiarid tropics. International Fertilizer Development Center, Muscle Shoals, Alabama, USA. Paper series - IFDC P-19.39p.

18) Srinivasan and Arnold 1994. Integration of a Basin-Scale Water Quality model with GIS. Water Resources Bulletin, Vol 30, pp: 453-462.

19) Srinivasan, $R$ and B.A. Engel. 1991 A knowledge based approach to extract input data from GIS.ASAE paper No. 91-7045, American Journal of Agriculture Engineers, St. Joseph, $M I$

20) Turban, E 1995 Decision support and expert system . Prentice Hall, USA

21) Williams, J.R., K.G. Renard, and P.T.Dyke. 1983 EPIC A new model for assessing erosion' effect on soil productivity. Journal of Soil and Water Conservation 38(5) : pp 381-383

22) Wilson, J.P. 1999 , Local, national and global applications of GIS in agriculture. Geographical Information System, Edited by Paul L., Goodchild M. F., Rhind D. W., Vol. 2 pp 981 - 995 